\title{
Implementasi Metode Analytical Hierarchy Process (AHP) untuk Evaluasi Pemasok Daging Sapi \\ (Studi Kasus : Restoran Nominomi Delight, Jakarta)
}

\author{
Implementation Of The Analytical Hierarchy Process (AHP) Method \\ For The Evaluation Of Beef Suppliers \\ (Case Study : Nominomi Delight Restaurant, Jakarta)
}

\author{
Fadhilah Hanifah *) \\ Elpawati Puspi Eko Wiranthi
}

Fakultas Sains dan Teknologi, UIN Syarif Hidayatullah, Jakarta, Indonesia

Email: fadhilahhanie@gmail.com *)

\begin{abstract}
The purpose of this research is to develop a performance appraisal method to get the priority order of four restaurant beef suppliers based on the weight of the selection criteria and by showing the indicators of each criterion, using the Vendor Performance Index and the Analytical Hierarchy Process (AHP) method. There are seven main criteria for assessing supplier performance, namely quality, cost, delivery, flexibility, responsiveness, solutions, and relationships which are then translated into thirty-eight sub criteria or indicators. With the AHP method, weights obtained from the seven criteria in the order of quality (0.371), cost (0.256), delivery (0.101), solution (0.078), flexibility (0.070), responsiveness (0.069), and relationship (0.055). The results of supplier selection based on the AHP method obtained the weight in the order of priority of suppliers, namely PT Sukanda Djaya (0.377). PT Indoguna Utama (0.349). Santosa Agrindo (0.146), and Amino Meat (0.128).
\end{abstract}

Keywords : supplier, supplier selection criteria, Vendor Permorfa Index (VPI), Analytichal Hierarchy Process (AHP)

\begin{abstract}
ABSTRAK
Tujuan penelitian ini adalah mengembangkan suatu metode penilaian kinerja untuk mendapatkan urutan prioritas dari empat pemasok daging sapi restoran berdasarkan bobot dari kriteria pemilihan dan dengan memperlihatkan indikator dari setiap kriteria, menggunakan Vendor Performa Index dan metode Analytical Hierarchy Process (AHP). Ada tujuh kriteria utama untuk menilai kinerja pemasok, yaitu quality, cost, delivery, flexibility, responsiveness, solutive, dan relationship yang kemudia dijabarkan menjadi tiga puluh delapan sub kriteria atau indikator. Dengan metode AHP diperoleh bobot dari ketujuh kriteria dengan urutan quality $(0,371)$, cost $(0,256)$, delivery $(0,101)$, solutive $(0,078)$, flexibility $(0,070)$, responsiveness $(0,069)$, dan relationship $(0,055)$. Adapun hasil pemilihan pemasok berdasarkan metode AHP diperoleh bobot dengan urutan prioritas pemasok yaitu PT Sukanda Djaya $(0,377)$. PT Indoguna Utama (0,349). Santosa Agrindo (0,146), dan Amino Meat $(0,128)$.
\end{abstract}

Kata Kunci : supplier, kriteria pemilihan supplier, Vendor Permorfa Index (VPI), Analytichal Hierarchy Process (AHP) 


\section{PENDAHULUAN}

\section{Latar Belakang}

Perubahan dinamis menuju globalisasi membawa praktik makan baru yang di dorong oleh keinginan akan status dan kenyaman (Mish, 2007:165). Gaya hidup masyarakat yang gemar mengkonsumsi produk instan disebabkan karena tuntutan pekerjaan, kemacetan, dan semakin banyak perempuan yang bekerja di luar rumah. Restoran NomiNomi Delight merupakan salah satu restoran yang menawarkan berbagai jenis menu makanan jepang dan memiliki 5 cabang di Jakarta dan sekitarnya. Selain menerima pesanan dine-in dan take-away dari konsumen langsung, NomiNomi Delight juga bermitra dengan perusahaan jasa pelayanan antar makanan seperti GoFood dan GrabFood. Salah satu faktor yang mendukung kelancaran bisnis di bidang kuliner adalah ketersediaan bahan baku pada restoran (Andayani, 2017:3). Berdasarkan data penjualan restoran, menu ramen beef menjadi paling dominan dan favorit bagi pelanggan restoran. Adapun jenis daging sapi yang dibutuhkan pada menu ramen beef adalah slice beef dan mince beef.

Restoran NomiNomi Delight memiliki empat pilihan supplier daging untuk keberlangsungan produksi restoran. Setiap supplier memiliki kelebihan dan kekurangan dalam memenuhi kebutuhan pasokan daging sapi. Dalam mengambil keputusan untuk memilih pemasok, evaluasi menjadi salah satu faktor penting dalam sehingga restoran dapat bersaing dengan restoran jepang lain dalam hal kepuasan, keuntungan dan memenuhi kebutuhan konsumen (Meindl (2010:20). Pemilihan supplier dilakukan berdasarkan karakteristik dari bahan baku terkait (Aramyan et al, 2006:50). Penelitian ini berupaya menganalisis kriteria yang berpengaruh dalam pemilihan supplier dengan Vendor Performa Index (VPI) berkerangka QCDFR atau quality, cost, delivery, flexibility, dan responsiveness, menggunakan metode AHP (Yadav, 2016).

\section{Rumusan Masalah}

Berdasarkan uraian diatas dapat dirumuskan permasalahan penelitian ini adalah sebagai berikut :

1. Bagaimana urutan prioritas kriteria dalam pemilihan supplier daging sapi pada restoran NomiNomi Delight?

2. Supplier daging sapi mana yang sebaiknya dipilih oleh restoran NomiNomi Delight berdasarkan metode AHP ?

3. Bagaimana implikasi manajerial yang tepat untuk keberlangsungan produksi retoran NomiNomi Delight?

\section{Tujuan}

Penelitian ini bertujuan untuk mengetahui urutan prioritas kriteria pemilihan supplier daging sapi sehingga dapat menentukan supplier daging sapi terbaik untuk dipilih serta menetapkan implikasi manajerial yang tepat untuk keberlangsungan produksi restoran NomiNomi Delight. 


\section{METODE PENELITIAN}

\section{Lokasi dan Waktu Penelitian}

Lokasi penelitian dilakukan pada sebuah restoran cepat saji NomiNomi Delight cabang utama yang berlokasi di Jl. Raya Pemuda No. 72-73 DE, Rawamangun, RT 001/08 Jati, Kecamatan Pulo Gadung, Kota Jakarta Timur, DKI Jakarta. Lokasi penelitian dipilih secara sengaja (purposive), dengan pertimbangan NomiNomi Delight adalah restoran halal yang menyediakan makanan Jepang dan sudah berdiri sejak tahun 2015 serta memiliki 5 cabang di daerah Jakarta dan sekitarnya. Pengambilan data dilakukan pada bulan Februari - Juli 2020

\section{Responden Penelitian}

Responden pada penelitian ini sebanyak 5 orang, yaitu CEO satu orang, Manajer Area 1 orang, bagian Purchasing 1 orang, dan bagian Produksi 2 orang. Teknik Pengambilan sampel dilakukan dengan judgment sampling dengan pertimbangan ke lima responden tersebut yang paling memungkinkan untuk di wawancara dan paling memahami kondisi bahan baku restoran.

\section{Metode Pengumpulan Data}

Metode yang digunakan dalam pengumpulan data pada penelitian ini meliputi wawancara dan observasi.

\section{Metode Pengolahan dan Analisis Data}

Metode analisis data dalam penelitian ini dilakukan dengan cara analisis kualitatif dan kuantitatif. Metode kualitatif menggunakan analisis deskripstif fan metode kuantitatif menggunakan metode Analytical Hierarchy Process (AHP) dan menggunakan alat bantu software yaitu Expert Choice 11.

\section{Analisis Deskriptif}

Data yang diperolah dari responden akan dianalisis secara deskriptif sebelum menuju tahap AHP. Metode analisis deskriptif bertujuan untuk mengetahui dan mendeskripsikan kriteria dan subkriteria pada bahan baku daging sapi restoran.

\section{Analytical Hierarchy Process (AHP)}

Mengacu pada teori Marimin dan Maghfiroh (2013:94) bahwa terdapat empat prinsip dalam menyelesaikan persoalan dengan analisis AHP, yaitu :

1. Penyusunan Hierarki Pemilihan Supplier Daging Sapi Restoran NomiNomi Delight, Jakarta.

Penyusunan hierarki dilakukan dengan mengidentifikasi pengetahuan atau informasi yang sedang diamati, mulai dari permasalahan kompleks disederhanakan menjadi elemen- elemen pokok dalam struktur hierarki. Penyususnan hierarki didapatkan dari hasil wawancara dengan CEO Restoran. Level pertama merupakan tujuan, level kedua merupakan kriteria, level ketiga merupakan sub kriteria dan level keempat merupakan alternatif.

2. Penilaian Setiap Level Hierarki

Penilaian melalui perbandingan berpasangan pada setiap elemen untuk 
melihat intensitas kepentingan kepentingan suatu elemen terhadap elemen lainnya. Nilai skala banding berpasangan dan definisi pendapat kualitatif dari skala perbandingan berpadangan dilihat berdasarkan teori Saaty (1990).

3. Penentuan Prioritas

Penentuan prioritas dilihat dari setiap level yang mendapatkan perhitungan bobot tertinggi dari hasil pengolahan menggunakan Expert choice 11.

4. Konsistensi Logis

Nilai rasio konsistensi haru 10\%, jika lebih maka penilaian setiap level masih acak dan belum konsisten, sehingga perlu melakukan wawancara ulang.

\section{HASIL PENELITIAN DAN PEMBAHASAN}

Kriteria dalam penelitian menggunakan pendekatan penelitian terdahulu dengan metode Vendor Performa Index dan wawancara dengan CEO Restoran, sedangkan subkriteria di dapatkan murni dari hasil wawancara dengan CEO Restoran sehingga diperoleh kritaria dan subkriteria sebagai berikut.

Tabel 1. Indikator Setiap Variabel Kriteria Pemilihan Supplier Daging Sapi Restoran NomiNomi Delight, Jakarta.

\begin{tabular}{|c|c|}
\hline Kriteria & Subkriteria \\
\hline Quality & $\begin{array}{l}\text { Warna merah dan masih segar } \\
\text { Pemotongan mince beef menggunakan mesin giling } \\
\text { Pemotongan Slice beef menggunakan mesin slice } \\
\text { Ukuran slice beef setebal } 1 \mathrm{~mm} \\
\text { Lemak daging sesuai permintaan } \\
\text { Daging tidak keras } \\
\text { Pemasok memiliki label Halal resmi dari MUI }\end{array}$ \\
\hline Cost & $\begin{array}{l}\text { Harga Daging Stabil } \\
\text { Harga Daging lebih murah dari harga pasar } \\
\text { Biaya pengirisan lebih murah } \\
\text { Biaya cincang lebih murah } \\
\text { Harga sudah termasuk biaya kirim atau gratis biaya kirim } \\
\text { Ada pengurangan harga atau diskon pada quantity tertentu }\end{array}$ \\
\hline Delivery & $\begin{array}{l}\text { Ketepatan waktu pengiriman yaitu } \mathrm{H}+2 \text { dari waktu order } \\
\text { Pengiriman menggunakan alat pendingin / chiller } \\
\text { Pengemasan daging dengan baik } \\
\text { Ketepatan jumlah timbangan mince beef } \\
\text { Ketepatan jumlah timbangan slice beef }\end{array}$ \\
\hline Flexibility & $\begin{array}{l}\text { Menerima perubahan jumlah order slice beef } \\
\text { Menerima perubahan jumlah order mince beef } \\
\text { Menerima perubahan waktu kirim slice beef } \\
\text { Menerima perubahan waktu kirim mince beef } \\
\text { Rentang waktu dari pemesanan ke pengiriman pendek }\end{array}$ \\
\hline Responsiveness & $\begin{array}{l}\text { Cepat dalam merespon permintaan slice beef } \\
\text { Cepat dalam merespon permintaan mince beef } \\
\text { Tanggap merespon pengaduan ketidaksesuaian orderan } \\
\text { Tanggap merespon ketidakpuasan konsumen } \\
\text { Pemasok memiliki banyak SDM yang kompeten }\end{array}$ \\
\hline Solutive & $\begin{array}{l}\text { Pemasok memiliki truck pengantar, Chiller, dan Pengemudi } \\
\text { Pemasok berbagi informasi libur, promo harga dan produk baru } \\
\text { Pemasok membantu restoran memenuhi kebutuhan dadakan } \\
\text { Pemasok bertanggung jawab ketika salah kirim pesanan } \\
\text { Pemasok turut memberi ide pada restoran saat kendala sulit }\end{array}$ \\
\hline
\end{tabular}


Tabel 1. Indikator Setiap Variabel Kriteria Pemilihan Supplier Daging Sapi Restoran NomiNom Jakarta (lanjutan)

\begin{tabular}{ll}
\hline & Pemasok memberi informasi dengan akurat \\
Relationship & Pemasok memberikan pelayanan terbaik dengan maksimal \\
& Komunikasi dengan pemasok terjalin dengan baik \\
& Pemasok 1 bulan sekali mengajak bertemu dan berdiskusi \\
& Pemasok peduli dengan kendala restoran \\
\hline
\end{tabular}

Adapun Alternatif pemasok berdasarkan pengalaman restoran selama beroperasi dari PT. Indoguna Utama, PT. Sukanda Djaya, Santosa Agrindo, dan Amino Meat. Sehingga struktur hierarki pemilihan supplier daging dapat di gambarkan seperti gambar dibawah ini.

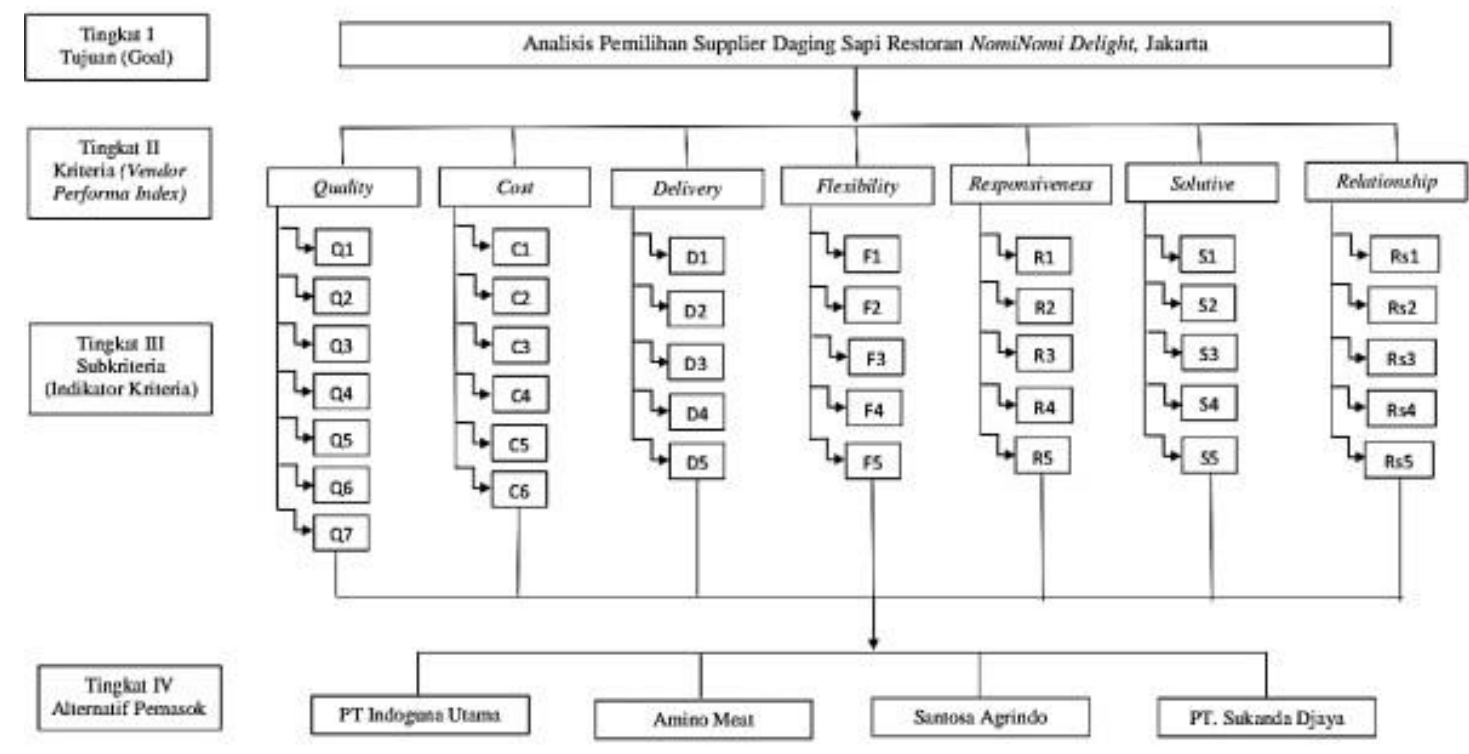

Gambar 1. Struktur Hierarki Pemilihan Supplier Daging Sapi Restoran NomiNomi Delight, Jakarta.

\section{Hasil Pengolahan Vertikal Elemen Kriteria}

Tabel 2. Hasil Pengolahan Vertikal Elemen Kriteria

\begin{tabular}{lcc}
\hline \multicolumn{1}{c}{ Kriteria } & Bobot & $\begin{array}{c}\text { Prior } \\
\text { itas }\end{array}$ \\
\hline Quality & 0,371 & 1 \\
Cost & 0,256 & 2 \\
Delivery & 0,101 & 3 \\
Flexibility & 0,070 & 5 \\
Responsiveness & 0,069 & 6 \\
Solutive & 0,078 & 4 \\
Relationship & 0,055 & 7 \\
\hline
\end{tabular}

Pengolahan vertikal menghasilkan prioritas pada elemen kriteria. Adapun hasil penilaian dari responden yang diolah menggunakan expert choice 11 mendapatkan hasil urutan priotitas utama untuk elemen kriteria adalah seperti pada table di atas. 


\section{Hasil Pengolahan Horizontal Elemen Alternatif Pemasok}

Pengolahan horizontal dilakukan untuk mengetahui alternatif pemasok terbaik dari setiap subkriteria dalam pemilian supplier daging sapi. Prosesn pengolahan horizontal dimulai dengan perbandingan antar elemen-elemen subkriteria dan elemen-elemen pada alternatif pemasok. Berikut tabel-tabel hasil pengolahan horizontal elemen alternatif pemasok terhadap elemen subkriteria dari semua kriteria pemilihan supplier daging sapi Restoran Nominomi Delight Jakarta.

Tabel 3. Hasil Pengolahan Horizontal Alternatif Pemasok pada Subkriteria dari Kriteria Quality

\begin{tabular}{|c|c|c|c|c|c|}
\hline \multirow{2}{*}{ Kriteria } & \multirow{2}{*}{ Subkriteria } & \multicolumn{4}{|c|}{ Alternatif Pemasok } \\
\hline & & Indoguna & Santori & Amino & Sukanda \\
\hline \multirow[t]{7}{*}{ Quality } & $\begin{array}{l}\text { Warna merah } \\
\text { dan masih segar }\end{array}$ & 0,437 & 0,136 & 0,089 & 0,338 \\
\hline & $\begin{array}{l}\text { Pemotongan } \\
\text { mincebeef } \\
\text { menggunakan } \\
\text { mesin giling }\end{array}$ & 0,384 & 0,107 & 0,139 & 0,371 \\
\hline & $\begin{array}{l}\text { Pemotongan } \\
\text { Slice beef } \\
\text { menggunakan } \\
\text { mesin slice }\end{array}$ & 0,453 & 0,085 & 0,107 & 0,355 \\
\hline & $\begin{array}{l}\text { Ukuran slice beef } \\
\text { setebal } 1 \\
\mathrm{~mm}\end{array}$ & 0,446 & 0,104 & 0,089 & 0,362 \\
\hline & $\begin{array}{l}\text { Lemak daging } \\
\text { sesuai } \\
\text { permintaan }\end{array}$ & 0,391 & 0,169 & 0,108 & 0,331 \\
\hline & Daging tidak keras & 0,381 & 0,188 & 0,093 & 0,338 \\
\hline & $\begin{array}{l}\text { Pemasok memiliki } \\
\text { label Halal resmi } \\
\text { dari MUI }\end{array}$ & 0,250 & 0,250 & 0,250 & 0,250 \\
\hline
\end{tabular}


Tabel 4. Hasil Pengolahan Horizontal Alternatif Pemasok pada Subkriteria dari Kriteria Cost

\begin{tabular}{llcccc}
\hline \multirow{2}{*}{ Kriteria } & \multicolumn{1}{c}{ Subkriteria } & \multicolumn{4}{c}{ Alternatif Pemasok } \\
\cline { 2 - 6 } & $\begin{array}{l}\text { Harga daging } \\
\text { Stabil }\end{array}$ & 0,298 & 0,141 & 0,082 & $\mathbf{0 , 4 7 9}$ \\
\cline { 2 - 6 } & $\begin{array}{l}\text { Harga daging } \\
\text { lebih murah dari } \\
\text { harga pasar }\end{array}$ & 0,315 & 0,199 & 0,104 & $\mathbf{0 , 3 8 2}$ \\
\cline { 2 - 6 } Cost & $\begin{array}{l}\text { Biaya } \\
\text { pengirisan lebih } \\
\text { murah }\end{array}$ & 0,317 & 0,210 & 0,168 & $\mathbf{0 , 3 9 5}$ \\
& $\begin{array}{l}\text { Biaya cincang } \\
\text { lebih murah }\end{array}$ & $\mathbf{0 , 3 4 7}$ & 0,138 & 0,228 & 0,228 \\
\cline { 2 - 6 } $\begin{array}{l}\text { Harga sudah } \\
\text { termasuk biaya } \\
\text { kirim atau gratis } \\
\text { ongkir }\end{array}$ & $\mathbf{0 , 3 9 5}$ & 0,170 & 0,146 & 0,289 \\
\hline $\begin{array}{l}\text { Ada } \\
\text { pengurangan } \\
\text { harga atau } \\
\text { diskon pada } \\
\text { quantity tertentu }\end{array}$ & $\mathbf{0 , 2 5 0}$ & $\mathbf{0 , 2 5 0}$ & $\mathbf{0 , 2 5 0}$ & $\mathbf{0 , 2 5 0}$ \\
\hline
\end{tabular}

Tabel 5. Hasil Pengolahan Horizontal Alternatif Pemasok pada Subkriteria dari Kriteria Delivery

\begin{tabular}{|c|c|c|c|c|c|}
\hline \multirow{2}{*}{ Kriteria } & \multirow{2}{*}{ Subkriteria } & \multicolumn{4}{|c|}{ Alternatif Pemasok } \\
\hline & & Indoguna & Santori & Amino & Sukanda \\
\hline \multirow{5}{*}{ Delivery } & $\begin{array}{l}\text { Ketepatan } \\
\text { waktu } \\
\text { pengiriman } \\
\text { H+2 } \\
\text { dari waktu order }\end{array}$ & 0,344 & 0,106 & 0,117 & 0,433 \\
\hline & $\begin{array}{l}\text { Pengiriman } \\
\text { menggunakan } \\
\text { alat pendingin / } \\
\text { Chiller }\end{array}$ & 0,346 & 0,227 & 0,115 & 0,313 \\
\hline & $\begin{array}{l}\text { Pengemasan } \\
\text { daging dengan } \\
\text { baik }\end{array}$ & 0,388 & 0,110 & 0,107 & 0,396 \\
\hline & $\begin{array}{l}\text { Ketepatan } \\
\text { jumlah } \\
\text { timbangan } \\
\text { mince beef }\end{array}$ & 0,413 & 0,122 & 0,111 & 0,354 \\
\hline & $\begin{array}{l}\text { Ketepatan } \\
\text { jumlah }\end{array}$ & 0,402 & 0,121 & 0,111 & 0,366 \\
\hline
\end{tabular}


Tabel 6. Hasil Pengolahan Horizontal Alternatif Pemasok pada Subkriteria dari Kriteria Solutive

\begin{tabular}{|c|c|c|c|c|c|}
\hline \multirow{2}{*}{ Kriteria } & \multirow{2}{*}{ Subkriteria } & \multicolumn{4}{|c|}{ Alternatif Pemasok } \\
\hline & & Indoguna & Santori & Amino & Sukanda \\
\hline \multirow{5}{*}{ Solutive } & $\begin{array}{l}\text { Pemasok } \\
\text { memiliki truck } \\
\text { pengantar, } \\
\text { chiller, dan } \\
\text { pengemudi }\end{array}$ & 0,294 & 0,098 & 0,127 & 0,481 \\
\hline & $\begin{array}{l}\text { Pemasok } \\
\text { berbagi } \\
\text { informasi libur, } \\
\text { promo harga, } \\
\text { dan produk baru }\end{array}$ & 0,302 & 0,118 & 0,124 & 0,456 \\
\hline & $\begin{array}{l}\text { Pemasok } \\
\text { membantu } \\
\text { restoran } \\
\text { memenuhi } \\
\text { kebutuhan } \\
\text { dadakan }\end{array}$ & 0,354 & 0,092 & 0,117 & 0,437 \\
\hline & $\begin{array}{l}\text { Pemasok } \\
\text { bertanggung } \\
\text { jawab ketika } \\
\text { salah kirim } \\
\text { pesanan }\end{array}$ & 0,294 & 0,124 & 0,115 & 0,469 \\
\hline & $\begin{array}{l}\text { Pemasok turut } \\
\text { memberi ide } \\
\text { pada restoran } \\
\text { saat keadaan } \\
\text { sulit }\end{array}$ & 0,309 & 0,112 & 0,111 & 0,468 \\
\hline
\end{tabular}

Tabel 7. Hasil Pengolahan Horizontal Alternatif Pemasok pada Subkriteria dari Kriteria Flexibility

\begin{tabular}{clcccc}
\hline \multirow{2}{*}{ Kriteria } & \multicolumn{1}{c}{ Subkriteria } & \multicolumn{4}{c}{ Alternatif Pemasok } \\
\cline { 2 - 5 } & $\begin{array}{l}\text { Menerima } \\
\text { perubahan } \\
\text { jumlah order } \\
\text { slice beef }\end{array}$ & 0,378 & 0,104 & 0,120 & $\mathbf{0 , 3 9 8}$ \\
\hline $\begin{array}{l}\text { Menerima } \\
\text { perubahan } \\
\text { jumlah order } \\
\text { Flexibility }\end{array}$ & 0,364 & 0,128 & 0,116 & $\mathbf{0 , 3 9 1}$ \\
\hline $\begin{array}{l}\text { mince beef } \\
\text { Menerima } \\
\text { perubahan } \\
\text { waktu kirim } \\
\text { slice beef }\end{array}$ & $\mathbf{0 , 4 4 0}$ & 0,100 & 0,116 & 0,344 \\
\hline $\begin{array}{l}\text { Menerima } \\
\text { perubahan } \\
\text { waktu kirim } \\
\text { mince beef }\end{array}$ & $\mathbf{0 , 4 2 4}$ & 0,124 & 0,117 & 0,335 \\
\hline $\begin{array}{l}\text { Rentang waktu } \\
\text { dari pemesanan } \\
\text { ke pengiriman } \\
\text { pendek }\end{array}$ & 0,297 & 0,108 & 0,137 & $\mathbf{0 , 4 5 8}$ \\
\hline
\end{tabular}


Tabel 8. Hasil Pengolahan Horizontal Alternatif Pemasok pada Subkriteria dari Kriteria Responsiveness

\begin{tabular}{|c|c|c|c|c|c|}
\hline \multirow{2}{*}{ Kriteria } & \multirow{2}{*}{ Subkriteria } & \multicolumn{4}{|c|}{ Alternatif Pemasok } \\
\hline & & Indoguna & Santori & Amino & Sukanda \\
\hline \multirow{5}{*}{ Responsiveness } & $\begin{array}{l}\text { Cepat dalam } \\
\text { merespon } \\
\text { permintaan silice } \\
\text { beef }\end{array}$ & 0,369 & 0,110 & 0,118 & 0,403 \\
\hline & $\begin{array}{l}\text { Cepat dalam } \\
\text { merespon permintaan } \\
\text { mince } \\
\text { beef }\end{array}$ & 0,298 & 0,104 & 0,117 & 0,481 \\
\hline & $\begin{array}{l}\text { Tanggap } \\
\text { merespon } \\
\text { pengaduan } \\
\text { ketidaksesuaian } \\
\text { orderan }\end{array}$ & 0,357 & 0,092 & 0,153 & 0,398 \\
\hline & $\begin{array}{l}\text { Tanggap } \\
\text { merespon } \\
\text { ketidakpuasan } \\
\text { konsumen }\end{array}$ & 0,354 & 0,119 & 0,122 & 0,405 \\
\hline & $\begin{array}{l}\text { Pemasok memiliki } \\
\text { banyak SDM yang } \\
\text { kompeten }\end{array}$ & 0,306 & 0,135 & 0,115 & 0,443 \\
\hline
\end{tabular}

Tabel 9. Hasil Pengolahan Horizontal Alternatif Pemasok pada Subkriteria dari Kriteria Relationship

\begin{tabular}{|c|c|c|c|c|c|}
\hline \multirow{2}{*}{ Kriteria } & \multirow{2}{*}{ Subkriteria } & \multicolumn{4}{|c|}{ Alternatif Pemasok } \\
\hline & & Indoguna & Santori & Amino & Sukanda \\
\hline \multirow{5}{*}{ Relationship } & $\begin{array}{l}\text { Pemasok memberi } \\
\text { informasi dengan } \\
\text { akurat }\end{array}$ & 0,292 & 0,134 & 0,107 & 0,467 \\
\hline & $\begin{array}{l}\text { Pemasok } \\
\text { memberikan } \\
\text { pelayanan terbaik } \\
\text { dengan maksimal }\end{array}$ & 0,302 & 0,117 & 0,102 & $\mathbf{0 , 4 7 9}$ \\
\hline & $\begin{array}{l}\text { Komunikasi } \\
\text { dengan pemasok } \\
\text { terjalin dengan } \\
\text { baik }\end{array}$ & 0,282 & 0,098 & 0,081 & $\mathbf{0 , 5 3 9}$ \\
\hline & $\begin{array}{l}\text { Pemasok } 1 \text { bulan } \\
\text { sekali mengajak } \\
\text { bertemu dan } \\
\text { berdiskusi }\end{array}$ & 0,289 & 0,117 & 0,105 & 0,489 \\
\hline & $\begin{array}{l}\text { Pemasok peduli } \\
\text { dengan kendala } \\
\text { restoran }\end{array}$ & 0,295 & 0,099 & 0,098 & $\mathbf{0 , 5 0 7}$ \\
\hline
\end{tabular}

Hasil pengolahan berupa bobot dari setiap perbandingan antar elemen alternatif pemasok terhadap elemen subkriteria dari kriteria quality, cost, delivery, solutive, flexibility, responsiveness, dan relationship dapat disimpulkan bahwa, PT. Sukanda Djaya sebagai pemasok dengan urutan bobot paling tinggi terbanyak dari seluruh elemen subkriteria. 


\section{Implikasi Manajerial}

Implikasi manajerial untuk restoran berdasarkan hasil penelitian, urutan prioritas dari tujuh kriteria yang menjadi acuan restoran dalam pemilihan supplier terbaik yaitu, quality, cost, delivery, solutive, flexibility, responsiveness, dan relationship. Adapun pentingnya restoran mengetahui urutan prioritas kriteria berdasarkan hasil penelitian adalah kriteria quality menjadi prioritas utama bagi restoran oleh sebab itu tentunya restoran siap mengeluarkan cost lebih untuk mendapatkan kualitas bahan baku terbaik untuk keberlangsungan produksi restoran. Sedangkan berdasarkan urutan alternatif pemasok, PT Sukanda Djaya mendapatkan bobot tertinggi, oleh karena itu maka restoran dapat melakukan proporsi pesanan lebih banyak dan lebih sering terhadap PT Sukanda Djaya. Restoran sebaiknya membuat SOP dan melakukan sosialisasi kembali kepada setiap pemasok daging sapi terkait kriteria dan subkriteria yang restoran butuhkan dalam pemenuhan bahan baku daging sapi.

\section{SIMPULAN DAN SARAN}

\section{Simpulan}

Urutan prioritas dari 7 kriteria yang digunakan restoran NomiNomi Delight dalam pemilihan supplier daging sapi terbaik dengan bobot nilainya masing-masing berdasarkan metode AHP yaitu quality $(0,371)$, cost $(0,256)$, delivery $(0,101)$, solutive $(0,078)$, flexibility $(0,070)$, responsiveness $(0,069)$, dan relationship $(0,055)$. Hal ini menunjukan kriteria quality merupakan kriteria paling penting dalam pemilihan supplier bahan baku daging sapi restoran NomiNomi Delight, Jakarta.

Berdasarkan pengolahan data dengan metode AHP dapat diketahui bahwa Sukanda Djaya merupakan supplier yang paling potensial dalam memenuhi kebutuhan bahan baku daging sapi restoran NomiNomi Delight dengan perolehan bobot nilai sebesar 0,377. Prioritas selanjutnya berdasarkan ranking pada metode AHP yang telah di dapatkan secara berturut-turut yaitu Indoguna $(0,349)$, Santosa Agrindo $(0,146)$ dan Amino Meat $(0,128)$.

Implikasi manajerial yang tepat untuk restoran adalah dengan melakukan proporsi pemesanan lebih banyak terhadap PT Sukanda Djaya dan melakukan sosialisasi kembali pada keempat pemasok yang bermitra terkait kriteria dan subkriteria daging sapi yang restoran butuhkan.

\section{Saran}

Sebaiknya, pihak manajemen restoran membuat SOP kriteria dan subkriteria dalam pemilihan supplier untuk memenuhi kebutuhan bahan baku daging sapi dan juga bisa diterapkan pada pemenuhan bahan baku lainnya agar mengantisipasi kekurangan bahan baku pada restoran. Selain itu berdasarkan kesimpulan, sebaiknya memilih Sukanda Djaya sebagai alternatif pemasok terbaik untuk memenuhi kebutuhan slice beef dan mince beef.

Berdasarkan keterbatasan penelitian, bagi peneliti selanjutnya diharapkan dapat melakukan wawancara pada pihak supplier dan akademisi atau konsultan bisnis yang paham terkait permasalahan penelitian. 


\section{DAFTAR PUSTAKA}

Andayani, S. Ay. (2017). "Pendekatan Manajemen Dalam Agribisnis" (Y. Farlina (ed.)). CV Media Cendikiawan Muslim. https://docplayer.info/91415915Manajemen-agribisnis- pendekatan-manajemen-dalam-agribisnis.html.

Aramyan, L., Ondersteijn, C. J. M., Kooten, O. Van, \& Oude Lansink, A. (2006). "Performance indicators in agri-food production chains". 49-66. https://doi.org/10.1007/1-4020-4693-6_5.

Marimin dan Maghfiroh, N. (2013). "Aplikasi Teknik Pengambilan Keputusan dalam Manajemen Rantai Pasok". IPB Press.

Meindl, S. C. dan P. (2010). "Supply Chain Management Strategy, Planning, and Operation Pearson".

Mish, J. (2007). "A Heavy Burden Of Identity: India, Food, Globalization, And Women". Research in Consumer Behavior, 11, 165-186. https://doi.org/10.1016/S0885- 2111(06)11008-X.

Saaty, T. L. (1990). "The analytic hierarchy process in conflict management. In International Journal of Conflict Management" (Vol. 1, Issue 1, pp. 47-68). https://doi.org/10.1108/eb022672.

Yadav Milind Kumar Sharma, V. (2016). "Journal of Modelling in Management Multicriteria supplier selection model using the analytic hierarchy process approach" Article information. Journal of Modelling in Management, 11. www.emeraldinsight.com. 